\title{
First analysis of the secretome of the canine heartworm, Dirofilaria immitis
}

\author{
James Geary ${ }^{1}$, Mohamed Satti ${ }^{1,4}$, Yovany Moreno ${ }^{2,5}$, Nicole Madrill', Doug Whitten ${ }^{3}$, Selwyn A Headley ${ }^{4,6}$, \\ Dalen Agnew ${ }^{1}$, Timothy Geary ${ }^{2}$ and Charles Mackenzie ${ }^{1 *}$
}

\begin{abstract}
Background: The characterization of proteins released from filariae is an important step in addressing many of the needs in the diagnosis and treatment of these clinically important parasites, as well as contributing to a clearer understanding of their biology. This report describes findings on the proteins released during in vitro cultivation of adult Dirofilaria immitis, the causative agent of canine and feline heartworm disease. Differences in protein secretion among nematodes in vivo may relate to the ecological niche of each parasite and the pathological changes that they induce.

Methods: The proteins in the secretions of cultured adult worms were run on Tris-Glycine gels, bands separated and peptides from each band analysed by ultra mass spectrometry and compared with a FastA dataset of predicted tryptic peptides derived from a genome sequence of $D$. immitis.

Results: This study identified 110 proteins. Of these proteins, 52 were unique to D. immitis. A total of 23 (44\%) were recognized as proteins likely to be secreted. Although these proteins were unique, the motifs were conserved compared with proteins secreted by other nematodes.

Conclusion: The present data indicate that D. immitis secretes proteins that are unique to this species, when compared with Brugia malayi. The two major functional groups of molecules represented were those representing cellular and of metabolic processes. Unique proteins might be important for maintaining an infection in the host environment, intimately involved in the pathogenesis of disease and may also provide new tools for the diagnosis of heartworm infection.
\end{abstract}

Keywords: Dirofilaria, Heartworm, Canine, Feline, Nematode, Filarial, Secretome, Proteins

\section{Background}

The filarial nematode Dirofilaria immitis, the aetiologic agent of heartworm infection in dogs and cats, is widely distributed in the United States, South America and parts of Europe and Asia [1]. The adult worms can be found mainly in the pulmonary arteries, and sometimes the right heart, atrium and vena cava in heavy infections; this differs from many other filariae that tend to favour lymphatic vessels. Infections with small numbers of adult D. immitis may be asymptomatic and have limited pathological effects; however, high adult worms loads usually cause exercise intolerance, a wet cough and lethargy in

\footnotetext{
*Correspondence: mackenz8@msu.edu

'Department of Pathobiology and Diagnostic Investigation, College of Veterinary Medicine, Michigan State University, East Lansing, MI 48824, USA Full list of author information is available at the end of the article
}

dogs [2]. Cats are inherently resistant to Dirofilarial infections and thus usually have much lower adult worm burdens than do dogs. However, as cats have a much smaller pulmonary arterial tree they are more susceptible to embolism. In addition, dirofilariasis in cats is often more difficult to diagnose due to lower loads and the differing clinical signs from those in dogs [2].

Although D. immitis has been controlled through several different strategies, the most successful has been the prophylactic administration of a range of drug combinations and administration schedules, most usually involving tablets or topical preparations containing a macrocyclic lactone (ML) anthelmintic to uninfected dogs and cats to protect them by killing infective $\mathrm{L}_{3}$ larvae and developing $\mathrm{L}_{4}$ larvae [3]; drugs in this class of agents are also microfilaricidal. MLs 
also affect adult worms, thus inducing long-term suppression in the production of microfilariae (mff) [4]. There are, however, concerns relative to the development of ML resistance [5,6]. A course of arsenical drugs, such as the currently preferred malarsomine, is adulticidal, although this regimen is not without risk to the animal due to the hepato- and nephron-toxicity of these compounds [7,8]; 'slow-kill' strategies for use of MLs in infected dogs have also been developed [9], and the potential for anti-Wolbachia treatment options to reduce transmission and pathological effects following adulticidal therapy is promising $[10,11]$.

It has long been recognized that parasitic nematodes release factors, primarily proteins, which alter the immune responses of their hosts [12-14]. Recently, the use of sophisticated mass spectroscopy-based approaches, coupled to genome and transcriptome sequencing, has enabled the identification of proteins released by Brugia malayi [15-17] and Heligmosomoides polygyrus polygyrus (now considered to represent $H$. bakeri- [18]) into culture medium $[19,20]$. Secreted proteins have also been characterized from the canine hookworm, Ancylostoma caninum [21], the plant parasitic nematode Meloidogyne incognita [22] and from Strongyloides stercoralis [23]. Not all of these nematode datasets were analyzed against complete genomes (or transcriptomes), and, therefore, some of the compilations may be less completely assigned than others. Nonetheless, it can be concluded that a large number of proteins have been detected in the secretome from these parasites, with marked differences observed among them. The complexity of the nematode secretome compromises the ability to define the most biologically important proteins through a systematic analysis. One approach to provide some focus to this question is to define the secreted proteins that are conserved among parasites that share a niche (e.g., tissue versus gastrointestinal tract), and to consider those shared between phylogenetically related organisms (for instance those in Clade III vs. Clade V; [24]). Thus far, the data sets for nematodes are limited to parasites from different clades and different habitats. The present study describes the secretome of $D$. immitis, as distinct from that of $B$. malayi, which resides in a different niche in the mammalian host.

A more pragmatic reason to study the composition of parasite secretomes is to identify the most abundant proteins released into host fluids and tissues which could be candidates for the development of new diagnostic tests, and possibly new treatments. Current diagnostic procedures for nematodes typically rely on poorly characterized or proprietary antigens or antibodies, or the counting of eggs in faecal specimens: the identification of abundantly secreted proteins may allow the development of tests which can assess worm burdens, a goal not readily attainable using current diagnostic tools [25].

\section{Methods}

\section{Parasite retrieval}

Eighty mixed sex, adult $D$. immitis worms were collected from the pulmonary vessels and right heart chamber from $\mathrm{mf}$ test-positive dogs immediately after euthanasia, and the healthy worms placed in the culture fluid, as described below. These procedures were approved by the Animal Use Committee of St. Matthew's University School of Veterinary Medicine (Grand Cayman, British West Indies). At the end of each $24 \mathrm{~h}$ period, immotile worms were removed from the culture system; thus, 56 worms were cultured on day 2 and 51 on day 3, the two days on which culture medium was collected for analysis.

\section{Parasite culture}

Worms were cultured in large Petri dishes (1 worm/ $4 \mathrm{~mL}$ medium, 5 worms per dish) at $39^{\circ} \mathrm{C}$ in RPMI 1640 medium, supplemented with $200 \mathrm{mM} \mathrm{L}$-glutamine, $20 \mathrm{mM}$ HEPES, $200 \mathrm{IU} / \mathrm{mL}$ penicillin, $200 \mathrm{IU} / \mathrm{mL}$ streptomycin, $25 \mu \mathrm{g} / \mathrm{mL}$ amphotericin B (Gibco Invitrogen, Grand Island, NY), 1\%w/v D-glucose and 1\%w/v sodium bicarbonate, $\mathrm{pH}$ 7.2. Medium was collected and changed every $24 \mathrm{~h}$. To limit potential contamination of the samples with host proteins, first-day medium was discarded. Medium from the subsequent 2 days was collected for molecular analysis. To determine the vitality of the worms, the change in colour $(\mathrm{pH})$ of the medium was monitored to verify that all worms present were actively metabolizing. Petri dishes that exhibited a colour change were used for analysis, whereas those that remained unchanged or contained immotile worms were discarded. Based on this protocol, medium from 107 worm-days of cultures was collected. On the third day, the concentration was decreased to 1 worm $/ 6 \mathrm{~mL}$. Protease inhibitors (Complete EASYpack Roche, Indianapolis, IN) were added to batches of $50 \mathrm{~mL}$ of collected medium.

\section{Protein preparation}

Immediately after the removal of adult worms, the medium samples were centrifuged at $1000 \times g$ for $5 \mathrm{~min}$ to pellet mff released during the incubation. The supernatant was removed, passed through a $0.22 \mu \mathrm{m}$ filter and frozen at $-20^{\circ} \mathrm{C}$ for shipment to Michigan State University. There, the combined volume $(775 \mathrm{~mL})$ was concentrated to $40 \mathrm{~mL}$ using an Amicon Ultra $3000 \mathrm{MWCO}$ (Millipore, Billerica, MA). Proteins were then precipitated using trichloroacetic acid (final concentration of $20 \%$ ). Pelleted proteins were washed with cold $\left(-20^{\circ} \mathrm{C}\right)$ acetone 3 times and allowed to air dry [15-17].

\section{Protein analysis}

Protein pellets were dissolved in $100 \mu \mathrm{L}$ sodium dodecyl sulfate - polyacrylamide gel electrophoresis (SDS-PAGE) sample buffer (50 mM Tris-HCl, 2\% SDS, 10\% glycerol,1\% 
$\beta$-mercaptoethanol, 12.5 mM EDTA, 0.02\% bromophenol blue, $\mathrm{pH}$ 6.8) and re-precipitated with chloroform:methanol (1:4). Pellets were re-solubilized in SDS-PAGE sample buffer and run on a BioRad Criterion precast $12.5 \%$ TrisGlycine gel at $50 \mathrm{~V}$ for $15 \mathrm{~min}$, followed by $120 \mathrm{~V}$ until the dye front reached the bottom of the gel ( $90 \mathrm{~min})$. The gel was fixed overnight in $40 \%$ methanol/20\% acetic acid, followed by staining with colloidal Coomassie Blue. The entire gel lane was sectioned into 10 equal slices, and each slice was digested in-gel, essentially as described previously [26]. Briefly, gel bands were dehydrated using $100 \%$ acetonitrile and incubated with $10 \mathrm{mM}$ dithiothreitol in $100 \mathrm{mM}$ ammonium bicarbonate, $\mathrm{pH} \sim 8$, at $56^{\circ} \mathrm{C}$ for $45 \mathrm{~min}$, dehydrated again and incubated in the dark with $50 \mathrm{mM}$ iodoacetamide in $100 \mathrm{mM}$ ammonium bicarbonate for $20 \mathrm{~min}$. Gel bands were then washed with ammonium bicarbonate and dehydrated again. Sequencing grade, modified trypsin was prepared to $0.01 \mu \mathrm{g} / \mu \mathrm{L}$ in $50 \mathrm{mM}$ ammonium bicarbonate and $\sim 50 \mu \mathrm{L}$ were added to each gel band, so that the gel was submerged. Bands were incubated at $37^{\circ} \mathrm{C}$ overnight. Extracted peptides were re-suspended in $20 \mu \mathrm{L} 2 \%$ acetonitrile/0.1\% trifluoroacetic acid.

A $10 \mu \mathrm{L}$ aliquot of each sample was automatically injected by a Waters nanoAcquity Sample Manager (www.waters.com) and loaded for $5 \mathrm{~min}$ on to a Waters Symmetry C18 peptide trap ( $5 \mu \mathrm{m}, 180 \mathrm{um} \times 20 \mathrm{~mm})$ at $4 \mu \mathrm{L} / \mathrm{min}$ in $2 \%$ acetonitrile $/ 0.1 \%$ formic acid. Bound peptides were eluted using a Waters nanoAcquity UPLC (Buffer $\mathrm{A}=99.9 \%$ water $/ 0.1 \%$ formic acid, Buffer $\mathrm{B}=99.9 \%$ acetonitrile $/ 0.1 \%$ formic acid) onto a Michrom MAGIC C18AQ column (3 $\mathrm{m}, 200 \mathrm{~A}, 100 \mathrm{U} \times 150 \mathrm{~mm}$, www.michrom.com) and eluted over $90 \mathrm{~min}$ with a gradient of $5 \% \mathrm{~B}$ to $35 \% \mathrm{~B}$ in $78 \mathrm{~min}$ at a flow rate of $1 \mu \mathrm{L} /$ min. Eluted peptides were sprayed into a ThermoFisher LTQ-FT Ultra mass spectrometer (www.thermo.com) using a Michrom ADVANCE nanospray source. Survey scans were taken in the FT (25000 resolution determined at $\mathrm{m} / \mathrm{z} 400$ ) and the top ten ions in each survey scan subjected to automatic low energy collision induced dissociation (CID) in the LTQ. The resultant MS/MS spectra were converted to peak lists using BioWorks Browser v3.3.1 (ThermoFisher) using the default parameters and the peptide masses were compared with a FastA dataset of predicted tryptic peptides derived from a genome sequence of $D$. immitis (P. Maser, personal communication; see http://nematodes.org/downloads/959nematodegenomes/ blast/db/Dirofilaria_immitis_v1.3_20110901.fna) and the NCBI database, including the Canis familiaris genome, using the Mascot algorithm v2.3 (www.matrixscience. com). Search parameters were restricted to allow up to two missed tryptic sites, fixed modification of carbamidomethyl cysteine, variable modification of oxidation of methionine, peptide tolerance of $+/-10 \mathrm{ppm}$ and MS/MS tolerance of 0.6 Da. The Mascot output was analyzed using Scaffold, v3.2, (www.proteomesoftware.com) to probabilistically validate protein identifications using the ProteinProphet algorithm [27]. Assignments validated above the Scaffold 95\% confidence filter were considered true. The data have been submitted to Tranche.

\section{Data analysis}

Blast2GO [28] was used to analyze the returned proteins as described elsewhere [15-17]. Briefly, an initial BLASTP search was performed against the non-redundant NCBI protein database. Subsequently, the annotation was completed using default parameters [29,30]. SecretomeP [31]: (http://www.cbs.dtu.dk/services/SecretomeP/) and SignalP [32]: (http://www.cbs.dtu.dk/services/SignalP/) were used to assess secretory motifs in the proteins.

\section{Results}

\section{Amount of protein}

Approximately $60 \mu \mathrm{g}$ of protein was collected from the D. immitis cultures. An initial SDS-PAGE run revealed a complex pattern of proteins (Figure 1). The three lanes were combined for tryptic digestion and MS/MS analysis. A second gel consisted of a single lane that contained the same amount of protein analyzed in the first PAGE run.

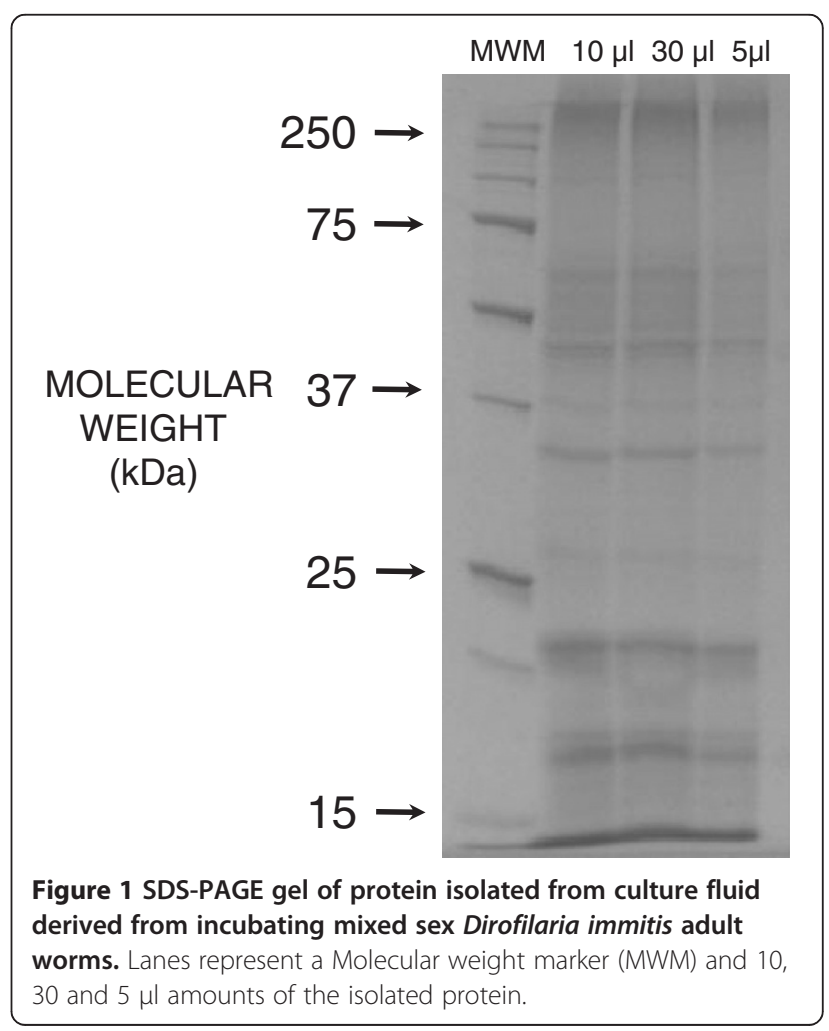




\section{Protein analysis}

The initial analysis revealed a total of 110 proteins. Results from the second run confirmed the first, with an additional 17 low abundance proteins appearing in this run. Following manual curation, redundant proteins (attributed to the same $D$. immitis locus) were removed, leaving a total of 110 proteins in this analysis of the heartworm secretome (Additional file 1: Table S1). Previous reports identified 193 proteins in the adult B. malayi secretome using similar methods [16].

Of these 110 proteins identified in the heartworm secretome, 52 were unique to $D$. immitis, not being described as being present in the $B$. malayi secretome [15-17]. Two of these proteins returned no BLAST hits, leaving 50 defined proteins unique in this context. The proteins found in common in the filariae were concentrated among the more abundant hits, but were distributed through the set, with the 15 most abundant proteins generally shared between the two filariae. Table 1 shows the 15 most abundant proteins detected in the heartworm secretome. The 15 most abundant proteins in the heartworm-unique sample are shown in Table 2. Of these unique defined proteins, 47 (90\%) had Gene Ontology (GO) terms assigned in Blast2GO.

Catalytic activity (GO:0003824) and binding (GO:0005488) were the two major molecular function categories, those using GO terms (Figure 2) and those according to biological process (Figure 3). This distribution was highly conserved with that reported for B. malayi [16]. The distribution of level 4 biological process GO terms was fairly flat (Figure 4), with no marked bias for particular functions. The category of 'cellular macromolecule metabolic process' was the most

Table 1 The 15 most abundant proteins detected in the Dirofilaria immitis secretome

\begin{tabular}{lc}
\hline SEQUENCE DESCRIPTION & ABUNDANCE RANK \\
\hline Phosphatidylethanolamine-binding protein & 1 \\
Ladder protein & 2 \\
MI domain containing protein & 3 \\
Transthyretin-like protein 5 & 4 \\
Glycosyl hydrolases family 31 protein & 5 \\
Transthyretin-like protein 5 & 6 \\
LL20 15kda ladder antigen & 7 \\
Transthyretin-like protein partial & 8 \\
Plasma glutamate carboxypeptidase-like & 9 \\
NADH-dependent fumarate reductase & 10 \\
Cysteine protease inhibitor & 11 \\
Abhydrolase domain containing isoform cra_a & 12 \\
Transthyretin-like protein partial & 13 \\
Immunogenic protein 3 & 14 \\
Exocyst complex component 2 & 15 \\
\hline
\end{tabular}

Table 2 The 15 most abundant unique proteins in the Dirofilaria immitis secretome

\begin{tabular}{lc}
\hline SEQUENCE DESCRIPTION & ABUNDANCE RANK \\
\hline Abhydrolase domain containing isoform cra_a & 12 \\
Glutathione s-transferase 1 & 18 \\
Elegans protein partially confirmed & 22 \\
by transcript evidence & 22 \\
cre-pqn-85 protein & 22 \\
Nipped-b-like protein & 26 \\
Pdz domain containing protein & 27 \\
Jheh1 & 30 \\
Alpha-actinin & 32 \\
Epoxide hydrolase 1 & 35 \\
Protein dek isoform 1 & 37 \\
Kh domain containing protein & 38 \\
Protein szt2 & 39 \\
Hypothetical protein LOAG_04081 [Loa loa] & 40 \\
Elongation factor tu homologue precursor & 44 \\
Pan domain containing protein &
\end{tabular}

frequent term in this category, while 'ribonucleotide binding' was the most frequent term in the set of returned level 4 molecular function GO terms (Figure 5). For both, the distribution of term frequency was generally similar to those reported for B. malayi [16].

Analysis for secretion signals by Secretome P and Signal P showed 10 (19\%) of the D. immitis unique proteins include a canonical signal sequence for secretion. An additional 13 (25\%) include peptide sequences associated with non-classical secretion pathways, for a total of 23 $(44 \%)$ that can be recognized as proteins likely to be secreted in some manner. This figure is somewhat less than the corresponding percentages previously reported for B. malayi [16].

Several mammalian proteins, clearly not of nematode origin, were also detected in the protein samples (data not shown). These proteins included keratin, titin and serum albumin, among others, but did not interfere with the characterization of the heartworm secretome. No bacterial proteins were present.

\section{Discussion}

The initial analysis revealed a secretome consisting of 110 proteins, identified through the analysis of $\sim 30 \mu \mathrm{g}$ protein collected during cultivation of adult heartworms. MS/MS analysis of the same amount of protein was repeated independently on the second gel; these results confirmed the first, with 17 additional low-abundance proteins being displayed in this run; manual curation revealed that 17 of the identified proteins were duplicates. The high agreement between independent replicates of 


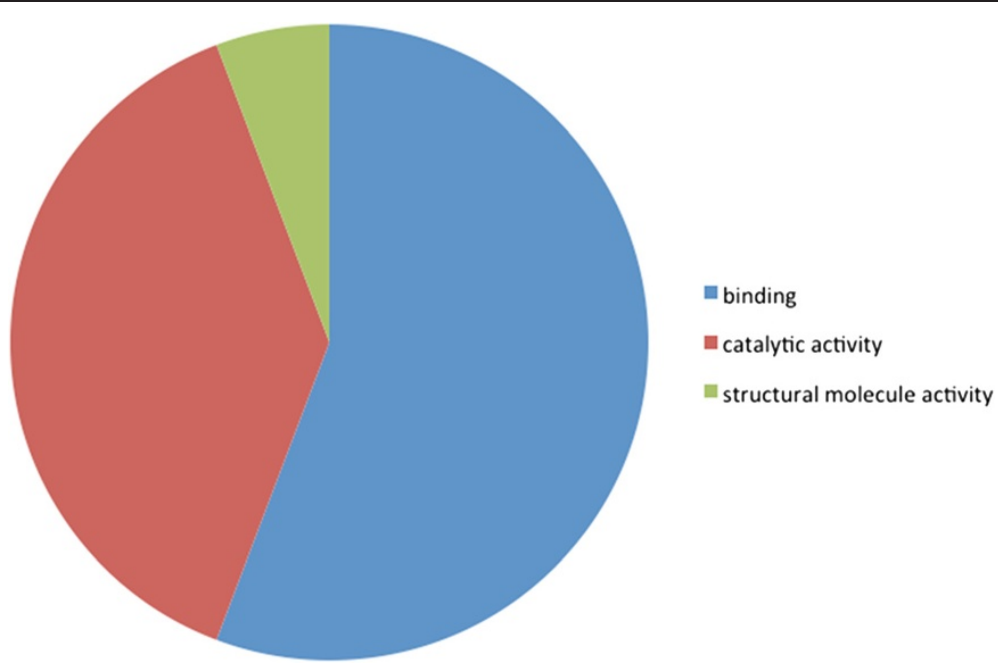

Figure 2 Dirofilaria immitis protein analysis: Distribution of the most abundant (level 2) molecular functions using GO terms.

the MS/MS analysis suggests that a reliable and reasonably complete accounting of the proteins present in this sample was obtained, in consideration of the amount of protein available and the intrinsic sensitivity of the methods. The 110 proteins identified in these two experiments (Additional file 1: Table S1) were combined for further analysis. Using similar methods, 193 proteins were reported in the adult $B$. malayi secretome from $\sim 100 \mu \mathrm{g}$ of protein, suggesting that the procedures generated similar efficiencies of protein recovery and identification [16].

Of the 110 proteins identified in the heartworm secretome, 52 were not present in the published secretome of B. malayi [15-17]. The degree of relatedness of the secretome composition of these two species was higher than that of either with the secretomes of the other nematode species for which comprehensive datasets are available (not shown) [18-22]; since these data were generated using different methods and produced quite different numbers of identified proteins from multiple developmental stages, a detailed species-species comparison is unwarranted at this time. As an example, however, the comparative data reveal that the secretomes of the filarial species are much more closely related (53\% identical) than either is to $H$. polygyrus, a gastrointestinal nematode in a different clade (V versus III; $<20 \%$ identical). It is possible to discern a set of 17 secretome proteins which are

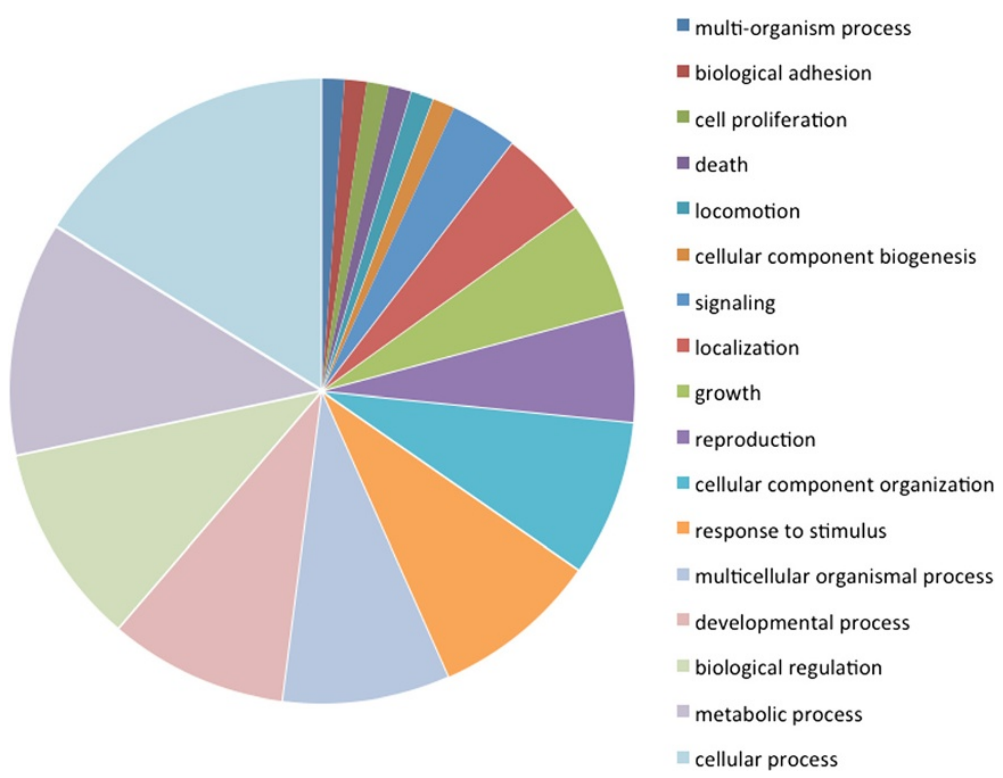

Figure 3 Dirofilaria immitis protein analysis: Distribution of the most abundant (level 2) biological process using GO terms. 


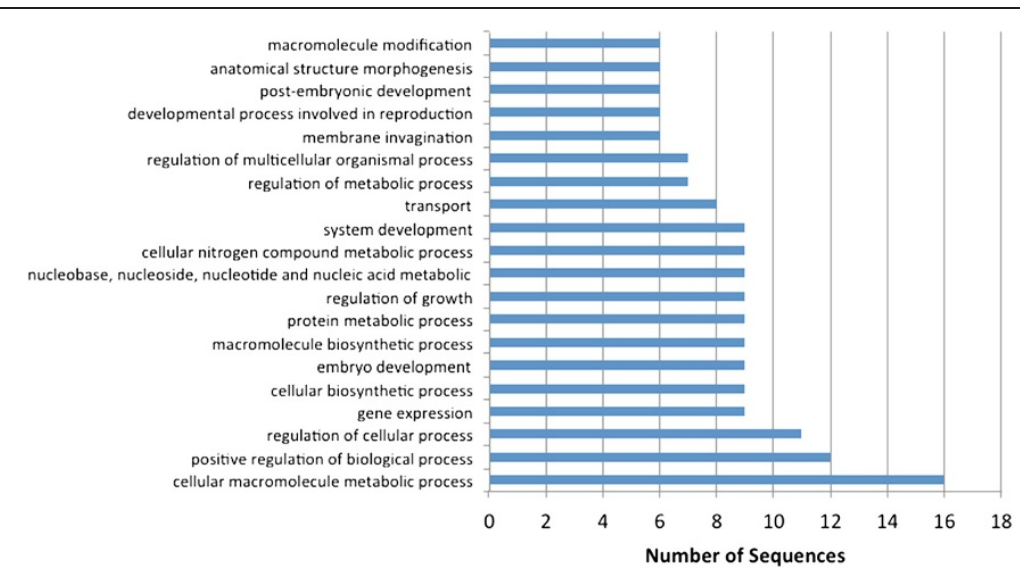

Figure 4 Dirofilaria immitis protein profile. Distribution of the top 20 most abundant (level 4) biological processes (GO terms).

common to species that parasitize mammals, including $D$. immitis (Table 3), and so constitute a minimal consensus secretome of species from distinct clades [23] which inhabit different niches as adults. All of these proteins, except cystatin, macrophage migration inhibition factor, triosephosphate isomerase and phosphatidylethanolaminebinding protein, have also been detected in the $M$. incognita secretome [21]. The functions embodied in this list can, in general, be associated with roles in modifying host responses or in protein-release pathways. The inclusion of additional nematode species in secretome analyses will enable this list to be refined, but the available data suggest that secretome composition may be highly adapted to the site of residence of these parasites. It is interesting, in this regard, that we did not find in the D. immitis secretome some classes of proteins which have been reported in the secretomes of both other nematodes, including B. malayi, such as a variety of proteases and globins. Whether their absence from the current secretome is due to the lower amount of heartworm protein available for this analysis or to a fundamental difference in the menu of secreted proteins among these species requires additional research.

The proteins identified in common in the filariae were distributed throughout the data set. However, the shared proteins were much more likely to be among the most, as opposed to the least abundant molecules, indicating a high correlation between proteins secreted in abundance by the two filariae. Two of the $D$. immitis-unique proteins returned no BLAST hits, leaving 50 defined proteins unique, in this context, in the D. immitis secretome. Of these proteins, $45(87 \%)$ could be assigned GO terms in Blast2GO. Catalytic activity (GO:0003824) and binding (GO:0005488) were the two major molecular function categories (Figures 2 \& 3), while cellular (GO:0009987) and metabolic (GO:0008152) processes were the two major biological process categories (Figures $2 \& 3$ ) for the heartworm-unique proteins. This distribution was, in general, quite conserved with that reported for proteins in the B. malayi secretome using similar methods [16]. Consideration of the functions of the heartworm-unique secretome did not identify any molecules with special relevance to the niche inhibited by this species, compared with that of $B$. malayi.

About $40 \%$ of the heartworm-unique proteins contained amino acid sequences that are associated with classical or non-classical secretion pathways. This figure is somewhat lower than the corresponding figure $(\sim 65 \%)$ reported for B. malayi using similar methods [16]. An explanation for this discrepancy is not readily apparent; additional data on the identification of proteins released in the host (as opposed to in culture) could resolve the biological relevance of their detection in these experiments. It should also be noted that many secreted proteins are now recognized as being released in exosomes, which

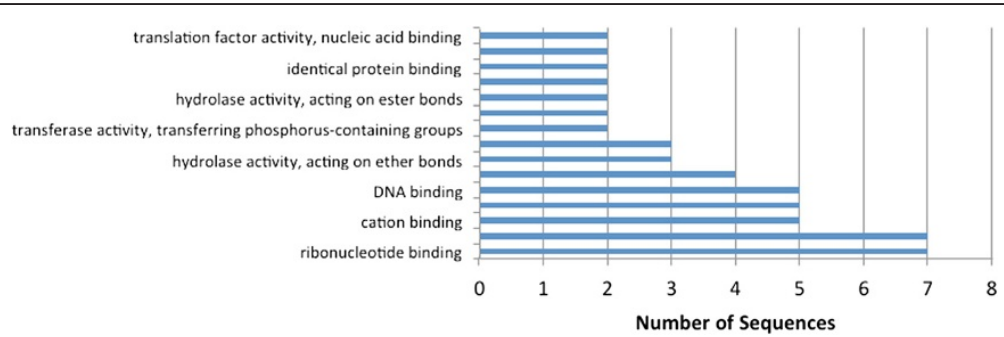

Figure 5 Dirofilaria immitis protein profile. Distribution of the most abundant (level 4) molecular functions (GO terms). 


\begin{tabular}{lc} 
Table 3 Proteins found in the Dirofilaria immitis \\
secretome with functions that are known to be usually \\
conserved in nematodes & ABUNDANCE RANK \\
\hline SEQUENCE DESCRIPTION & 1 \\
\hline Phosphatidylethanolamine-binding protein & 4 \\
Transthyretin family proteins & 7 \\
LL20 15 kDa ladder antigen & 11 \\
Cysteine protease inhibitor/cystatin & 14 \\
Immunogenic protein 3 & 18 \\
Glutathione-S-transferase & 20 \\
Lectins (galectin/galactoside-binding protein) & 23 \\
Actin & 42 \\
Enolase & 46 \\
Triosephosphate isomerase & 50 \\
Macrophage migration inhibition factor & 52 \\
Heat shock protein 70 & 54 \\
Fatty acid-bunding protein & 77 \\
Protein disulfide isomerase & 61 \\
Cyclophilin & 90 \\
Fumarase & 100 \\
Aldolase & \\
\hline
\end{tabular}

List compiled from published secretomes [15-18,28-30].

represent a significant pathway in eukaryotic and prokaryotic organisms [33,34]. Indeed, exosomes-mediated secretion events have been detected in the $C$. elegans excretory canal [35]. Evidence is not available on the anatomical localization of exosomes in parasitic nematode secretory systems, but many proteins detected in nematode secretomes, including actin, elongation factors, aldolase, enolase, HSP70 and cyclophilin, are common components of mammalian exosomes (http://www.exocarta.org/exosome_markers). A recent report identified 27 Onchocerca ochengi proteins recovered from nodules [36], including many homologs of secretome proteins in other filariae. The majority of the O. ochengi proteins lacked secretion signals and are associated with exosomes in other organisms; these data support the relevance of the antigens detected in vitro and suggest that the role of exosomes, as a source of secreted proteins, warrants further investigation.

The impact of $D$. immitis infections on companion animal health and veterinary practice in endemic areas cannot be overstated. In endemic areas, the prevalence of infection can be as high as $20 \%$ in areas in which prophylaxis treatment is irregular [1]. The development and introduction of the highly efficacious and relatively inexpensive ML-based regimens for prophylaxis have produced one of the most successful mass drug administration programs in history. However, there are emerging concerns of resistance to the MLs most commonly used for heartworm prevention [6,7]. Data obtained from this experiment may assist in addressing this situation in several ways. First, current methods of testing for prophylactic activity against $D$. immitis are exceptionally time-constrained, as they monitor the onset of microfilaremia in treated dogs, which occurs $\sim 8$ months after infection [1]. A biomarker based on abundantly secreted proteins might allow detection of worms that survive the prophylactic regimen shortly after infection, and the proteins reported here are candidates for the development of such a test. Similarly, a number of current diagnostic tests based on antigen detection have been advanced for the diagnosis of $D$. immitis infection, but all of them have some problems with sensitivity and none is associated with a reported parasite protein [37]. A legitimate goal is the development of a test that can accurately predict adult worm burdens $[1,38]$, which can be an important factor in deciding on a course of treatment for infected animals. A test based on the most abundantly secreted parasite proteins may be better able to fulfil that role. Antigenbased diagnostic tests for human filarial infections have similar limitations, including the lack of well-described antigens in some tests, which have not been selected based on abundance in serum, concerns about sensitivity and an uncertain correlation with adult worm burden [39-43].

From a therapeutic standpoint, efforts to limit survival or development of heartworms with immunological interventions, such as vaccination, could be enhanced if proteins essential for the success of an infection were targeted as vaccine antigens. Previous work in this area seems to have been typically focused on parasite proteins that generated significant immune responses in dogs [44], which is not necessarily a predictor of value as a protective antigen. Instead, down-stream experimental work on the functional role of secreted proteins could identify candidates for which a strong antibody response would prevent establishment of an infection. A menu of secreted proteins, provided here, is essential for that work to proceed. This same line of reasoning suggests that the proteins identified may yield novel therapeutic targets. At least some of these secreted proteins may be critical for the survival of the parasite within the host. Any interference with their function via the administration of a therapeutic antibody may have a detrimental effect on the parasite's ability to remain viable, offering a possible alternative to the current arsenical-based strategy to cure established infections [1]. As the composition of the secretome varies according to life-cycle stage and sex in B. malayi $[16,17]$, it will be important to determine the contribution to the current $D$. immitis secretome from male, female and mff before advancing into new research in this area. 
The data obtained from this experiment yielded some information on putative functions of these proteins, which may help to illuminate the difference between the niches exploited by the various worms whose secretomes are compiled. As D. immitis resides in the bloodstream of the host, it is reasonable to expect some level of difference between both the gut-dwelling $H$. polygyrus and the lymph-residing $B$. malayi, which can be seen in these data. Of the 110 identified proteins, 52 (47\%) were unique to $D$. immitis compared to the nematode secretomes compiled previously.

It is known that a number of proteins are commonly conserved across nematodes species and are from this current study are also found in D. immitis (Table 3). A few of the proteins characterized as unique share a common family with proteins secreted by $B$. malayi. For instance, galectin was highly abundant in the $B$. malayi secretome, but the closest homolog in the D. immitis secretome was a galactoside-binding lectin family protein, which presumably has a similar or related functional role. However, a BLASTp analysis revealed that the $D$. immitis genome encodes a predicted protein that is almost identical to the B. malayi galectin (not shown), but which was not secreted proteins. Similarly, the glutathione s-transferase 1 found in the heartworm secretome was related to a homolog identified in the B. malayi secretome [16-18], but the closest homolog of the $B$. malayi protein in the D. immitis genome (data not shown) was not found in the current study. The implications of these findings are not clear; the functional conservation of these protein families in the secretomes of the two filarial species does not account for the discrepancy in secretion of the most closely related proteins between the two species.

A hypothesis driving investigations into the composition of the $D$. immitis secretome is that at least some of them should be adapted for the task of living in blood. Protease inhibitors and proteins that detoxify oxygen radicals are likely important for any parasite in a host; candidates specifically pertinent for life the bloodstream are not readily apparent. The family of transthyretin-like proteins is highly represented in the heartworm secretome. This family is represented by a large number of genes in C. elegans [45], the functions of which are largely unknown. However, transport functions have been associated with this family [45], and it would be advantageous to study their biological function in this regard in nematodes in general and tissue-dwelling species in particular.

The anatomy of secretory apparatuses in adult D. immitis is unknown. In general, the adult filariid secretory system is either glandular or tubular. In each kind of system, a duct links the secretory cells and opens to the exterior through a secretory pore that may be muscularly controlled [46]. In addition to a discrete secretory compartment analogous to that found in mff [6], proteins may be discharged into the medium from uterine fluid during the release of $\mathrm{mff}$ by females, from the release of cuticleassociated materials or from defecation of incompletely digested parasite or host proteins. Several canine proteins were detected in these samples; whether they arose from incomplete washing of the worms or from excretion via the faecal route cannot be concluded. The contribution of proteins secreted versus those excreted or discharged into the medium (e.g., intestinal waste and/or uterine fluid) could be resolved by further experiments.

\section{Conclusions}

This is the first report of the secretory proteome of $D$. immitis, which lives in the circulatory system rather than the lymphatic vessels (B. malayi). Adult $D$. immitis were collected from dogs immediately after euthanasia and cultured for 3 days in RPMI 1640 media. This media was processed and yielded 110 proteins, 52 of which have not been reported in the secretomes of any other nematodes studied to date. Although these proteins were unique, their functional categories and motifs are generally similar to those of proteins released by other nematode species.

\section{Additional file}

Additional file 1: Table S1. The secretome of Dirofilaria immitis.

\section{Abbreviations}

ML: Macrocyclic lactone; HARD: Heartworm Associated Respiratory Distress; mff: Microfilariae; GO: Gene ontology; HEPES: (4-(2-hydroxyethyl)-1piperazineethanesulfonic acid); NCBI: National Center for Biotechnology Information; SDS-PAGE: Sodium dodecyl sulfate-polyacrylamide gel electrophoresis; LC-MS/MS: Liquid chromatography tandem mass spectroscopy.

\section{Competing interests}

The authors declare that they have no competing interests.

\section{Authors' contributions}

JG carried out preparation of the parasite material, the proteome analysis and the writing of the manuscript. MS, DA, NM, YM and SAH were all involved in the collection and preparation of the parasite material. TG was involved in the conception of the project, and CDM the project conception, collection of parasite material and the writing of the manuscript. All authors read and approved the manuscript.

\section{Acknowledgements}

This study was supported by the Companion Animal Fund of the College of Veterinary Medicine, Michigan State University, the Canadian Natural Science and Engineering Council (NSERC), the Canada Research Chairs program and the Fonds québécois de la recherche sur la nature et les technologies (FQRNT) Centre for Host-Parasite Interactions. We are most grateful to Detroit Animal Control (Harry Ward) and to St Mathews University, Grand Cayman for the use of their clinical facilities. We thank Dr. Kanyuira Gikonyo, Department of Agriculture, Grand Cayman, for his valuable assistance.

\section{Author details}

${ }^{1}$ Department of Pathobiology and Diagnostic Investigation, College of Veterinary Medicine, Michigan State University, East Lansing, MI 48824, USA. ${ }^{2}$ Institute of Parasitology, McGill University, Ste-Anne-de-Bellevue, QC H9X 3V9, Canada. ${ }^{3}$ Department of Plant Science, Michigan State University, East Lansing, MI 48824, USA. ${ }^{4}$ School of Veterinary Medicine, St Mathew's 
University, Orlando, Grand Cayman. ${ }^{5}$ Harvard School of Public Health, Boston, MA 02115, USA. ${ }^{6}$ Current address: Laboratory of Veterinary Pathology, Faculty of Veterinary Medicine, Universidade Norte do Paraná, Arapongas, PR, Brazil.

Received: 18 April 2012 Accepted: 13 June 2012

Published: 10 July 2012

\section{References}

1. McCall JW, Genchi C, Kramer LH, Guerrero J, Venco L: Heartworm disease in animals and humans. Adv Parasitol 2008, 66:193-285.

2. Hoch $\mathrm{H}$, Strickland $\mathrm{K}$ : Canine and feline dirofilariasis: life cycle, pathophysiology, and diagnosis. Compend Contin Educ Vet 2008, 30:133-140.

3. Bowman DD, Mannella C: Macrocyclic lactones and Dirofilaria immitis microfilariae. Top Companion Anim Med 2011, 26:160-172.

4. Lok JB, Knight DH, Selavka CM, Eynard J, Zhang Y, Bergman RN: Studies of reproductive competence in male Dirofilaria immitis treated with milbemycin oxime. Trop Med Parasitol 1995, 46:235-240.

5. Bourguinat C, Keller K, Bhan A, Peregrine A, Geary T, Prichard R: Macrocyclic lactone resistance in Dirofilaria immitis. Vet Parasitol 2011, 181:388-392.

6. Geary TG, Bourguinat C, Prichard RK: Evidence for macrocyclic lactone anthelmintic resistance in Dirofilaria immitis. Top Companion Anim Med 2011, 26:186-192.

7. McTier TL, McCall JW, Dzimianski MT, Raynaud JP, Strickland JE: Use of melarsomine dihydrochloride (RM 340) for adulticidal treatment of dogs with naturally acquired infections of Dirofilaria immitis and for clinical prophylaxis during reexposure for 1 year. Vet Parasitol 1994, 55:221-233.

8. McCall JW, McTier TL, Dzimianski MT, Raynaud JP, Holmes RA: Clinical prophylactic activity of melarsomine dihydrochloride (RM 340) against Dirofilaria immitis in heartworm-naive beagles exposed to natural infection in three southeastern states. Vet Parasitol 1994, 55:205-219.

9. McCall JW: The safety-net story about macrocyclic lactone heartworm preventives: a review, an update, and recommendations. Vet Parasitol 2005, 133:197-206.

10. McCall JW, Genchi C, Kramer L, Guerrero J, Dzimianski MT, Supakorndej P, Mansour AM, McCall SD, Supakorndej N, Grandi G, Carson B: Heartworm and Wolbachia: therapeutic implications. Vet Parasitol 2008, 158:204-214.

11. Kramer L, Grandi G, Passeri B, Gianelli P, Genchi M, Dzimianski MT, Supakorndej P, Mansour AM, Supakorndej N, McCall SD, McCall JW: Evaluation of lung pathology in Dirofilaria immitis-experimentally infected dogs treated with doxycycline or a combination of doxycycline and ivermectin before administration of melarsomine dihydrochloride. Vet Parasitol 2011, 176:357-360

12. Maizels RM, Balic A, Gomez-Escobar N, Nair M, Taylor MD, Allen JE: Helminth parasites-masters of regulation. Immunol Rev 2004, 201:89-116

13. Harnett $W$, Harnett MM: Therapeutic immunomodulators from nematode parasites. Expert Rev Mol Med 2008, 10:e18.

14. Hewitson JP, Grainger JR, Maizels RM: Helminth immunoregulation: the role of parasite secreted proteins in modulating host immunity. Mol Biochem Parasitol 2009, 167:1-11.

15. Hewitson JP, Harcus YM, Curwen RS, Dowle AA, Atmadja AK, Ashton PD, Wilson A, Maizels RM: The secretome of the filarial parasite, Brugia malayi: proteomic profile of adult excretory-secretory products. Mol Biochem Parasitol 2008, 160:8-21.

16. Moreno Y, Geary TG: Stage- and gender-specific proteomic analysis of Brugia malayi excretory-secretory products. PLoS Negl Trop Dis 2008, 2:e326.

17. Bennuru S, Meng Z, Ribeiro JM, Semnani RT, Ghedin E, Chan K, Lucas DA, Veenstra TD, Nutman TB: Stage-specific proteomic expression patterns of the human filarial parasite Brugia malayi and its endosymbiont Wolbachia. Proc Natl Acad Sci USA 2011, 108:9649-9654

18. Hewitson JP, Harcus Y, Murray J, van Agtmaal M, Filbey KJ, Grainger JR, Bridgett S, Blaxter ML, Ashton PD, Ashford DA, Curwen RS, Wilson RA, Dowle AA, Maizels RM: Proteomic analysis of secretory products from the model gastrointestinal nematode Heligmosomoides polygyrus reveals dominance of venom allergen-like (VAL) proteins. J Proteomics 2011, 74:1573-1594.

19. Behnke JM, Menge DM, Noyes $\mathrm{H}$ : Heligmosomoides bakeri: a model for exploring the biology and genetics of resistance to chronic gastrointestinal nematode infections. Parasitology 2009, 136:1565-1580.
20. Moreno Y, Gros PP, Tam M, Segura M, Valanparambil R, Geary TG, Stevenson MM: Proteomic analysis of excretory-secretory products of Heligmosomoides polygyrus assessed with next-generation sequencing transcriptomic information. PLoS Negl Trop Dis 2011, 5:e1370.

21. Mulvenna J, Hamilton B, Nagaraj SH, Smyth D, Loukas A, Gorman JJ: Proteomics analysis of the excretory/secretory component of the bloodfeeding stage of the hookworm, Ancylostoma caninum. Mol Cell Proteomics 2009, 8:109-121.

22. Bellafiore S, Shen Z, Rosso M-N, Abad P, Shih P, Briggs SP: Direct identification of the Meloidogyne incognita secretome reveals proteins with host cell reprogramming potential. PLoS Path 2008, 4:e1000192.

23. Soblik H, Younis AE, Mitreva M, Renard BY, Kirchner M, Geisinger F, Steen H, Brattig NW: Life cycle stage-resolved proteomic analysis of the excretome/secretome from Strongyloides ratti - identification of stagespecific proteases. Mol Cell Proteomics 2011, 10:M111.010157.

24. Blaxter ML: Nematoda: genes, genomes and the evolution of parasitism. Adv Parasitol 2003, 54:101-195.

25. Gioia G, Lecova L, Genchi M, Ferri E, Genchi C, Mortarino M: Highly sensitive multiplex PCR for simultaneous detection and discrimination of Dirofilaria immitis and Dirofilaria repens in canine peripheral blood. Vet Parasitol 2010, 172:160-163.

26. Shevchenko A, Wilm M, Vorm O, Mann M: Mass spectrometric sequencing of proteins silver-stained polyacrylamide gels. Anal Chem 1996, 68:850-858.

27. Nesvizhskii Al, Keller A, Kolker E, Aebersold R: A statistical model for identifying proteins by tandem mass spectrometry. Anal Chem 2003, $75: 4646-4658$

28. Conesa A, Gotz S, Garcia-Gomez JM, Terol J, Talon M, Robles M: Blast2GO: a universal tool for annotation, visualization and analysis in functional genomics research. Bioinformatics 2005, 21:3674-3676.

29. Myhre S, Tveit H, Mollestad T, Laegreid A: Additional gene ontology structure for improved biological reasoning. Bioinformatics 2006, 22:2020-2027.

30. Mulder NJ, Apweiler R, Attwood TK, Bairoch A, Bateman A, Binns D, Bork P, Buillard V, Cerutti L, Copley R, Courcelle E, Das U, Daugherty L, Dibley M, Finn R, Fleischmann W, Gough J, Haft D, Hulo N, Hunter S, Kahn D, Kanapin A, Kejariwal A, Labarga A, Langendijk-Genevaux PS, Lonsdale D, Lopez R, Letunic I, Madera M, Maslen J, et al: New developments in the InterPro database. Nucleic Acids Res 2007, 35:D224-D228.

31. Bendtsen JD, Jensen LJ, Blom N, Von Heijne G, Brunak S: Feature-based prediction of non-classical and leaderless protein secretion. Protein Eng Des Sel 2004, 17:349-356.

32. Petersen TN, Brunak S, von Heijne G, Nielsen H: SignalP 4.0: discriminating signal peptides from transmembrane regions. Nat Methods 2011, 8:785-786.

33. Mathivanan S, Simpson RJ: ExoCarta: a compendium of exosomal proteins and RNA. Proteomics 2009, 9:4997-5000.

34. Raimondo F, Morosi L, Chinello C, Magni F, Pitto M: Advances in membranous vesicle and exosome proteomics improving biological understanding and biomarker discovery. Proteomics 2011, 11:709-720.

35. Liegeois S, Benedetto A, Garnier J-M, Schwab Y, Labouesse M: The V0-ATPase mediates apical secretion of exosomes containing Hedgehogrelated proteins in Caenorhabditis elegans. J Cell Biol 2006, 173:949-961.

36. Cho-Ngwa F, Zhu X, Metuge JA, Daggfeldt A, Grönvik K-O, Orlando R, Atwood JA, Titanji VP: Identification of in vivo released products of Onchocerca with diagnostic potential, and characterization of a dominant member, the OV1CF intermediate filament. Infect Genet Evol 2011, 11:778-783.

37. Courtney $\mathrm{CH}$, Zeng Q-Y: Comparison of heartworm antigen test kit performance in dogs having low heartworm burdens. Vet Parasitol 2001, 96:317-322.

38. Wei GJ, Blair LS, Ewanciw DV, Malatesta PF: Use of parasite antigen detection to monitor the success of drug therapy in Dirofilaria immitis-infected dogs. J Parasitol 1986, 72:737-740.

39. Weil GJ, Lammie PJ, Weiss N: The ICT Filariasis Test: a rapid-format antigen test for diagnosis of Bancroftian filariasis. Parasitol Today 1997, 13:401-404.

40. Harnett W, Bradley JE, Garate T: Molecular and immunodiagnosis of human filarial nematode infections. Parasitology 1998, 117(Suppl):S59-S71.

41. Walther M, Muller R: Diagnosis of human filariasis (except onchocerciasis). Adv Parasitol 2003, 53:149-193.

42. Ayong LS, Tume CB, Wembe FE, Simo G, Asonganyi T, Lando G, Ngu JL: Development and evaluation of an antigen detection dipstick assay for the diagnosis of human onchocerciasis. Trop Med Int Health 2005, 10:228-233. 
43. Weil GJ, Ramzy RMR: Diagnostic tools for filariasis elimination programs. Trends Parasitol 2006, 23:78-82.

44. Grieve RB, Wisnewski N, Frank GR, Tripp CA: Vaccine research and development for the prevention of filarial nematode infections. Pharm Biotechnol 1995, 6:737-768. 32.

45. Richardson SJ, Hennebry SC, Smith BJ, Wright HM: Evolution of the thyroid hormone distributor protein transthyretin in microbes, C. elegans and vertebrates. Ann NY Acad Sci 2005, 1040:448-451.

46. Wharton D: A Functional Biology of Nematodes. Baltimore: The Johns Hopkins University Press; 1986.

doi:10.1186/1756-3305-5-140

Cite this article as: Geary et al.: First analysis of the secretome of the canine heartworm, Dirofilaria immitis. Parasites \& Vectors 2012 5:140.

\section{Submit your next manuscript to BioMed Central and take full advantage of:}

- Convenient online submission

- Thorough peer review

- No space constraints or color figure charges

- Immediate publication on acceptance

- Inclusion in PubMed, CAS, Scopus and Google Scholar

- Research which is freely available for redistribution 